\title{
Migration outflows and optimal migration policy: rules versus discretion
}

\author{
Ismael Issifou ${ }^{1}$ (iD) Francesco Magris ${ }^{2}$
}

Received: 11 May 2016 / Accepted: 9 March 2017 / Published online: 22 March 2017

(C) ISEG 2017

\begin{abstract}
We study the effects of more open borders on return migration and show that migrants are more likely to return to the origin country when migration rules are softened, because this implies that they could more easily re-migrate if return migration is unsuccessful. As a result, softening migration rules leads to lower net inflows than is generally acknowledged. We show that if government follows rules to shape the optimal migration policy, it will choose more open "borders" than were its behaviour to be discretionary. However, this requires an appropriate commitment technology. We show that electoral accountability may be a solution to the commitment problem. As a matter of fact, observed softer immigration rules in western countries suggest the effectiveness of such a mechanism.
\end{abstract}

Keywords Return migration · Optimal migration policy · Time consistency

JEL Classification E61 $\cdot$ F220 $\cdot$ J150

\footnotetext{
Ismael Issifou

ismael.issifou@univ-orleans.fr

Francesco Magris

francesco.magris@univ-tours.fr

1 University of Orléans, CNRS, LEO, UMR 7322, F45067, Orléans, France

2 University "François Rabelais" of Tours and CNRS, LEO, UMR 7322, F45067,

Orléans, France
} 